\title{
Studi Desain Generator Magnet Permanen Fluks Radial pada Pembangkit Listrik Tenaga Angin Kecepatan Putaran Rendah
}

\author{
Adeguna Ridlo Pramurti ${ }^{1}$ \\ ${ }^{1}$ Universitas Tanri Abeng \\ Jalan Swadarma Raya No. 58, Ulujami, Pesanggrahan, Jakarta Selatan 12250 \\ e-mail: adegunapramurti@gmail.com
}

\begin{abstract}
Abstrak-Generator magnet permanen fluks radial adalah mesin yang efektif untuk diaplikasikan pada sistem pembangkit listrik tenaga angin kecepatan rendah. Rugi magnetik akibat celah udara atau torsi denyut adalah salah satu masalah yang dapat menyebabkan penurunan performa tegangan keluaran dan daya keluaran pada generator jenis ini. Pada penelitian ini, topologi yang digunakan adalah stator ganda generator magnet permanen fluks radial. Topologi tersebut diharapkan mampu meningkatkan fluks listrik yang dihasilkan oleh kumparankumparan stator. Tujuan penelitian ini adalah untuk meningkatkan tegangan keluaran dan daya keluaran generator menggunakan metode desain pemasangan lebar gigi-gigi stator. Ada 3 variabel pada metode desain ini. Ketiga variabel desain mampu menurunkan nilai torsi denyut. Namun, ketiganya menyebabkan ketidakstabilan putaran generator. Hal ini disebabkan oleh peningkatan distribusi frekuensi torsi denyut. Ketiga variabel mampu meningkatkan tegangan keluaran generator dan daya keluaran generator masing-masing mencapai $3.94 \%$ dan 3.3\%. Peningkatan tegangan keluaran dan daya keluaran generator tidak terlalu signifikan disebabkan oleh peningkatan distribusi frekuensi torsi denyut yang mencapai $162 \%$.
\end{abstract}

Kata kunci: daya keluaran, generator magnet permanen fluks radial, pemasangan lebar gigi-gigi stator, stator ganda, dan tegangan keluaran.

\begin{abstract}
Radial flux permanent magnet generators are effective for application to low speed wind power generation systems. Magnetic loss due to air gap or called cogging torque is one of the problems that can cause a decrease in the output voltage and output power performance of this type of generator. In this study, the topology used is a dual stator radial flux permanent magnet generator. The topology is expected to increase the electrical flux produced by the stator coils. The purpose of this study is to increase the output voltage and output power of the generator using the stator teeth pairing design method. There are 3 variables in this design method. The three variables have been able to decrease the value of cogging torque. However, the three design variables have made the generator more unstable. This is due to an increase in the cogging torque frequency distribution. The three variables have been able to increase the generator output voltage and the generator output power respectively reached $3.94 \%$ and $3.3 \%$. The increase in output voltage and output power of the generator is not too significant due to an increase in the cogging torque frequency distribution which reached $162 \%$, karena itu tuliskan temuan atau kontribusi utama dari naskah sebaik mungkin dengan singkat.
\end{abstract}

Keywords: cogging torque, dual stator, radial flux permanent magnet generator, output power, and output voltage

\section{PENDAHULUAN}

Energi terbarukan telah berkembang di Indonesia. Energi angin merupakan salah satu energi terbarukan yang telah dimanfaatkan dan dikembangkan di Indonesia dengan ratarata potensi kecepatan angin yang dapat dikonversi menjadi energi listrik adalah sebesar $5 \mathrm{~m} / \mathrm{s}$. Energi angin tersebut tersebar di berbagai lokasi meliputi daerah pantai selatan pulau Jawa, Nusa Tenggara Timur, dan Sulawesi Selatan [1].

Kecepatan angin $5 \mathrm{~m} / \mathrm{s}$ dikategorikan sebagai kecepatan rendah untuk memutar turbin angin. Menurut penelitian [2], generator tanpa magnet permanen tidak efektif untuk pembangkit listrik kecepatan rendah. Generator tersebut memerlukan putaran tinggi sebagai penggerak mula agar menghasilkan medan magnet.

Pada penelitian [3], [4], teknologi magnet permanen generator efektif diaplikasikan pada sistem pembangkit listrik kecepatan rendah. Keuntungan menggunakan magnet permanen adalah karena dapat menghasilkan medan magnet sendiri tanpa perlu eksitasi dan tanpa disipasi daya listrik Rugi magnetik akibat adanya celah udara merupakan salah satu hal yangg perlu diperhatikan pada generator magnet. Hal tersebut dikarenakan oleh distribusi fluks magnetik dan kerapatan fluks magnetik akibat reluktansi celah udara menyebabkan penurunan performa tegangan keluaran dan daya keluaran generator [5].

Pada penelitian [6], dibahas tentang desain untuk mereduksi rugi magnetik dan rugi celah udara pada 
generator permanen magnet fluks radial. Rugi-rugi tersebut disebabkan oleh pengaruh torsi denyut yang berada di celah udara antara stator dan rotor. Nilai efektif dan distribusi keragaman frekuensi torsi denyut dapat diminimalkan menggunakan metode desain pemasangan lebar gigi-gigi stator. Terdapat pengaruh energi pada celah udara terhadap nilai efektif dan distribusi frekuensi torsi denyut. Apabila nilai torsi denyut dapat diminimalkan, harapannya adalah daya keluaran generator dapat meningkat dan getaran mesin dapat diminimalkan. Distribusi frekuensi yang tidak stabil dapat menurunkan performa mesin karena menyebabkan getaran dan arus eddy.

Penelitian [6] menggunakan topologi desain stator ganda pada generator magnet permanen fluks radial untuk parameter kecepatan angin $5 \mathrm{~m} / \mathrm{s}$. Stator ganda merupakan kombinasi dari generator magnet permanen fluks radial dengan inner-stator dan outer-stator. Kombinasi kedua topologi stator tersebut dimaksudkan untuk meningkatkan fluks listrik yang dihasilkan oleh kumparan-kumparan stator. Desain generator dimodelkan menggunakan aplikasi femm 4.2 dan disimulasikan dengan bahasa pemrograman lua.

\section{STUdi PUSTAKA}

Topologi desain stator ganda generator magnet permanen fluks radial adalah ketika generator memiliki stator yang berada di bagian dalam rotor (outer-rotor) dan stator yang berada di bagian luar rotor (inner-rotor). Pada penelitian [8]-[10], telah dibahas mengenai manfaat innerrotor dan outer-rotor ketika dikombinasikan pada stator ganda generator magnet permanen fluks radial. Pada topologi inner-rotor memiliki keunggulan struktur mekanis yang kuat, sedangkan pada topologi outer-rotor adalah memanfaatkan ukuran diamater yang lebih besar untuk menghasilkan daya keluaran tinggi.

Pemilihan jenis magnet merupakan faktor penting [11]. Salah satu jenis magnet yang biasa digunakan pada generator radial adalah neodymium ferrite boron (NdFeB). Magnet $\mathrm{NdFeB}$ adalah material magnetic dari jenis atom logam tanah jarang (rare earth). Atom pembentukknya adalah neodymium $(\mathrm{Nd}), 14$ atom besi $(\mathrm{Fe})$, dan 1 atom boron (B).

Keunggulan magnet permanen NdFeB dibanding beberapa jenis magnet lain adalah memiliki kepadatan torsi yang tinggi. Keunggulan lainnya adalah magnet NdFeB cocok untuk diaplikasikan pada generator radial. Hal ini dikarenakan dimensi magnet yang lebih sederhana dan kerapatan fluks magnetik yang lebih besar [12]. Pada generator radial kecepatan rendah [13], magnet $\mathrm{NdFeB}$ lebih cocok digunakan dibandingkan jenis magnet lain, seperti SmCo dan ferrite.

\section{METODE}

\section{A. Pemodelan}

Secara garis besar, penelitian ini merupakan pemodelan, simulasi, pengujian, dan analisis pada generator magnet permanen fluks radial. Penelitian ini berbasis pengujian menggunakan perangkat lunak. Pemodelan dan simulasi dilakukan sebagai gambaran identifikasi sistem atau alat yang sesungguhnya, karakteristik sistem juga dibuat serupa mungkin. Proses ini untuk memudahkan peneliti memodifikasi dan memprediksi sistem agar tidak menimbulkan resiko kerusakan dan menjamin efisiensi proses. Hal ini dikarenakan lebih mudah dan hemat waktu. Nilai yang dihasilkan pemodelan dan simulasi diharapkan dapat mendekati hasil sesungguhnya.

Pemodelan generator adalah untuk turbin angin kecepatan rendah. Putaran generator adalah sebesar 300 rpm. Nilai faktor perpindahan yang digunakan dalam penelitian ini adalah 0.86 dan perpindahan sudut stator adalah $12^{\circ}$. Magnet permanen yang digunakan adalah $\mathrm{NdFeB} \mathrm{N52.} \mathrm{Spesifikasi} \mathrm{arus} \mathrm{beban} \mathrm{penuh} \mathrm{dan} \mathrm{resistansi}$ fasa pada penelitian ini berturut-turut sebesar 1.5 ampere dan $43.9963 \mathrm{ohm}$. Parameter generator ditunjukkan pada Tabel 1 dan Tabel 2.

$$
\begin{gathered}
N_{T D}=\frac{N_{P} \times N_{S}}{F P B\left(N_{P,} N_{S}\right)} \\
\alpha_{\mathrm{NI}}=\frac{360^{a}}{\mathrm{~N}_{\mathrm{ID}}}
\end{gathered}
$$

Pengamatan nilai torsi denyut ditentukan oleh jumlah peristiwa torsi denyut $\left(\mathrm{N}_{\mathrm{TD}}\right)$ dan sudut mekanik putaran mesin $\left(\alpha_{M}\right)$ [14]. Persamaan (1) menunjukkan bahwa $N_{T D}$ berbanding lurus dengan jumlah kutub magnet rotor $\left(\mathrm{N}_{\mathrm{P}}\right)$ dan jumlah slot stator $\left(\mathrm{N}_{\mathrm{S}}\right)$, tetapi berbanding terbalik dengan faktor persekutuan tersebesar dari $\mathrm{N}_{P}$ dan $\mathrm{N}_{s}$. Persamaan (2) menunjukkan bahwa $\alpha_{M}$ merupakan rasio sudut putaran penuh mesin terhadap $\mathrm{N}_{\mathrm{TD}}$.

\section{B. Desain Pemasangan Lebar Gigi-gigi Stator}

Metode desain ini dimaksudkan untuk mengurangi energi pada celah udara $\left(\mathrm{W}_{\mathrm{A}}\right)$ yang disebabkan adanya pengaruh interaksi magnetik antara stator dan rotor pada generator [14], seperti ditunjukkan pada persamaan (3). $\mathrm{W}_{\mathrm{A}}$ dipengaruhi oleh stack length stator $\left(\mathrm{L}_{\mathrm{S}}\right)$, radius magnet permanen rotor $\left(R_{1}\right)$, radius stator $\left(R_{2}\right)$, permeabilitas udara $\left(\mu_{0}\right)$, permeansi relatif celah udara $(\mathrm{G})$, kelipatan persekutuan terkecil dari $\mathrm{N}_{\mathrm{S}}$ dan $\mathrm{N}_{\mathrm{P}}\left(\mathrm{N}_{\mathrm{K}}\right)$, dan kerapatan fluks magnetik (B).

$$
\begin{gathered}
W_{A}=\frac{2 \pi L_{s}\left(R_{2}^{2}-R_{I}^{2}\right)}{4 \mu_{0}} \times \sum_{n=0}^{\infty} G_{R N_{R}} \times B_{R N_{R}} \times \cos n N_{K} a_{n} \\
G_{\mathrm{nN}}=\frac{1}{n \pi} \times \frac{N_{I}}{N_{K}}\left(\sin n N_{K} \frac{x}{2}\right)+\left(\sin n N_{K} \frac{y}{2}\right) x
\end{gathered}
$$

Persamaan (4) merupakan fungsi permeansi relatif pada celah udara $\left(\mathrm{G}_{\mathrm{nNK}}\right)$ [14]. Berdasarkan persamaan (5) dengan nilai " $x$ " dan " $y$ " yang ditunjukkan pada Tabel 3, nilai permeansi relatif pada celah udara $\left(\mathrm{G}_{\mathrm{nNK}}\right)$ akan sama dengan 0 ketika $\mathrm{n}$ bernilai genap dan mendekati akan nol ketika bernilai positif. Hal tersebut menyebabkan energi celah udara dapat diminimalkan. Nilai torsi denyut $(\tau)$ dapat dibuat mendekati nol berdasarkan persamaan (6). 


$$
\begin{gathered}
\operatorname{sinnN} N_{L} \frac{a}{2}+\sin n N_{L} \frac{b}{2}=0 . \\
\tau=\frac{2 \pi L_{L}\left(R_{2}^{2}-R_{L}^{2}\right)}{2 \mu_{0}} \times \sum_{n=0}^{\infty} G_{n N_{L}} \times B_{n N_{L}} \times \operatorname{sinn} N_{L} a
\end{gathered}
$$

Gambar 1 merupakan desain awal dari stator ganda generator magnet permanen fluks radial. Lebar gigi stator "x" dan gigi stator " $y$ " adalah sama, yaitu 9 derajat mekanik. Pada Gambar 2 menunjukkan bahwa lebar gigi stator " $\mathrm{x}$ " dan lebar gigi stator " $y$ " terdapat perbedaan akibat dari metode desain pemasangan lebar gigi-gigi stator.

Tabel 1. Parameter stator generator magnet permanen fluks radial [6].

\begin{tabular}{|l|c|c|}
\hline \multirow{2}{*}{} & \multicolumn{2}{|c|}{ Stator } \\
\cline { 2 - 3 } & Inner-stator & Outer-stator \\
\hline Diameter bagian luar (mm) & 205 & 280 \\
\hline Diameter bagian dalam (mm) & 150 & 243 \\
\hline Stack length $(\mathrm{mm})$ & 30 & 30 \\
\hline Jumlah slot & 30 & 30 \\
\hline Material stator & M-47 Steel & M-47 Steel \\
\hline Lebar celah udara & 1 & 1 \\
\hline Diameter kawat & 0.8 & 0.8 \\
\hline Coil fill factor & 0.8 & 0.8 \\
\hline
\end{tabular}

Tabel 2. Parameter rotor generator magnet permanen fluks radial [6].

\begin{tabular}{|l|c|c|}
\hline \multirow{2}{*}{} & \multicolumn{2}{|c|}{ Rotor } \\
\cline { 2 - 3 } & Inner-rotor & Outer-rotor \\
\hline Diameter bagian luar (mm) & 229 & 241 \\
\hline Diameter bagian dalam (mm) & 207 & 219 \\
\hline Ketebalan magnet & 6 & 6 \\
\hline Jumlah kutub & 20 & 20 \\
\hline Material magnet & NdFeB N52 & NdFeB N52 \\
\hline
\end{tabular}

Tabel 3. Variabel nilai "x" dan "y".

\begin{tabular}{|c|c|c|}
\hline Variabel & $\mathrm{x}$ (derajat mekanik) & $\mathrm{y}$ (derajat mekanik) \\
\hline A & 7.6 & 10.4 \\
\hline B & 11 & 11 \\
\hline C & 6.5 & 11.5 \\
\hline
\end{tabular}

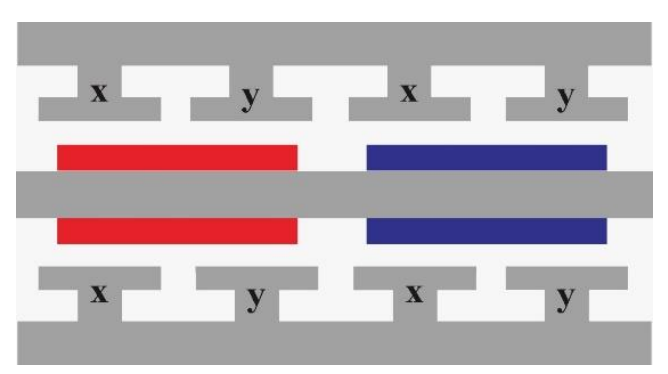

Gambar 1. Skema awal gigi stator generator magnet permanen fluks radial.

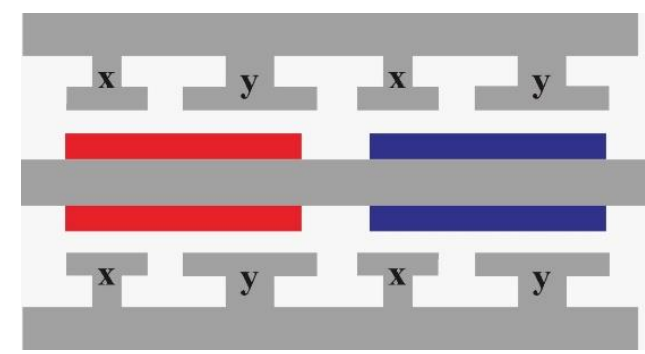

Gambar 2. Skema desain pemasangan lebar gigi-gigi stator pada gigi stator generator magnet permanen fluks radial.

\section{Persamaan Tegangan dan Daya Generator Radial}

Berdasarkan hukum Faraday, GGL induksi pada generator radial $\left(\mathrm{E}_{\mathrm{i}}\right)$ berbanding lurus dengan jumlah lilitan (N) dan perubahan nilai fluks magnet yang melalui suatu kumparan $(\mathrm{d} \emptyset)$ berbanding terhadap perubahan waktu $(\mathrm{dt})$. Di sisi lain jumlah lilitan dikalikan perubahan nilai fluks magnet sebanding dengan perubahan relatif nilai fluks gandeng yang melalui suatu kumparan [38]. Hal tersebut ditunjukkan pada persamaan (7).

$$
E_{\mathrm{i}}=N \frac{d \emptyset}{d t}=\frac{d \psi}{d t} x
$$

Ggl induksi juga dipengaruhi oleh perubahan relatif fluks gandeng terhadap perubahan waktu $(\mathrm{d} \psi)$ dan perubahan posisi (dt). Perubahan relatif fluks gandeng terhadap posisi mengacu pada kecepatan rotor per detik ( $\left.\mathrm{v}_{\text {rotor }}\right)$. Pada penelitian ini kecepatan rotor adalah $5 \mathrm{~m} / \mathrm{s}$. Hal tersebut ditunjukkan pada persamaan (8). Pada kasus ini, besarnya fluks gandeng yang melalui suatu kumparan didefinisikan sebagai hasil kali jumlah lilitan dengan integral kerapatan fluks magnet (B) pada elemen area permukaan bidang (dS) dan vektor normal terhadap area permukaan bidang $(\bar{n} \mathrm{dS})$. Hal ini ditunjukkan pada persamaan (9).

$$
E_{\mathrm{i}}=\frac{d \psi}{d z} \times \frac{d \psi}{d t}=v_{\text {rotor }} \times \frac{d \psi}{d z} \times
$$

$$
\psi=N \oint \bar{B} \times \bar{n} d S .
$$

Daya per fasa pada generator radial $(\mathrm{P})$ ditentukan oleh kuadrat arus beban penuh $\left(\mathrm{I}_{\mathrm{FL}}\right)$ dan resistansi beban pada kondisi beban penuh $\left(\mathrm{R}_{\mathrm{FL}}\right)$, seperti yang ditunjukkan pada persamaan (10). Untuk menentukan $\mathrm{R}_{\mathrm{FL}}$, ditunjukkan pada persamaan (11). Pada kondisi beban penuh, impedansi beban diasumsikan hanya berupa resistansi. Persamaan (12) menunjukkan tegangan terminal generator $\left(\mathrm{v}_{\mathrm{T}}\right)$ yang dipengaruhi oleh ggl induksi $\left(\mathrm{E}_{\mathrm{A}}\right)$, arus (I), resistansi (R), dan reaktansi induktif $\left(\mathrm{X}_{\mathrm{L}}\right)$. 


$$
P=I_{F L} \times R_{F L}
$$

$$
\begin{gathered}
R_{F L}=\sqrt{\left(\frac{e}{I_{F L}}\right)^{2}-X_{L}^{2}-R .} \\
V_{T}=e-I\left(R+X_{L}\right) .
\end{gathered}
$$

\section{HASIL DAN PEMBAHASAN}

Pada hasil penelitian dibahas tentang pengaruh torsi denyut terhadap daya keluaran generator. Ada 4 variabel yang dibahas, yaitu desain awal generator atau sebelum dimodifikasi dengan metode desain pemasangan lebar gigigigi stator, variabel $\mathrm{A}$, variabel $\mathrm{B}$, dan variabel $\mathrm{C}$.

\section{A. Hasil Desain Awal Generator}

Pada desain awal generator, daya keluaran maksimal yang dicapai adalah $1070 \mathrm{~W}$. Gambar 3 menunjukkan grafik hasil torsi denyut pada satu putaran penuh. Pada Tabel 4 menunjukkan nilai efektif torsi denyut sebesar $1.214 \mathrm{Nm}$ dan distribusi frekuensi torsi denyut sebesar 0.080 .

Tegangan keluaran tiap fasa pada desain awal sebesar $169 \mathrm{~V}$, resistansi tiap fasa pada kondisi beban penuh adalah 121.2 $\Omega$, arus beban penuh adalah $2.25 \mathrm{~A}$, dan daya tiga fasa adalah $757 \mathrm{~W}$. Sedangkan berdasarkan persamaan 13, daya maksimal yang dapat dicapai mesin adalah sebesar $1070 \mathrm{~W}$. Grafik hasil tegangan pada desain awal generator ditunjukkan pada Gambar 4.

$$
P=\sqrt{2} \times P_{\text {total }} \times
$$

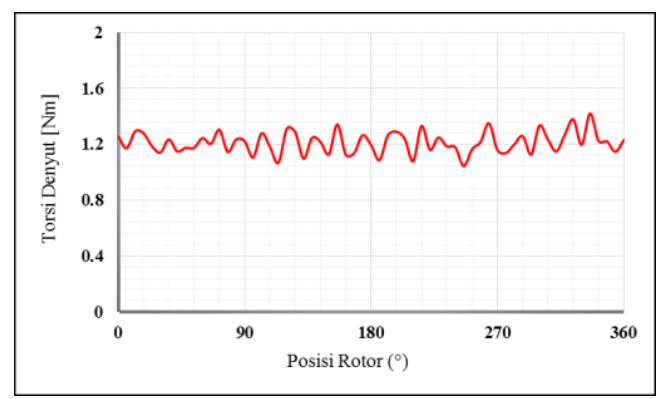

Gambar 3. Grafik nilai torsi denyut pada desain awal generator.

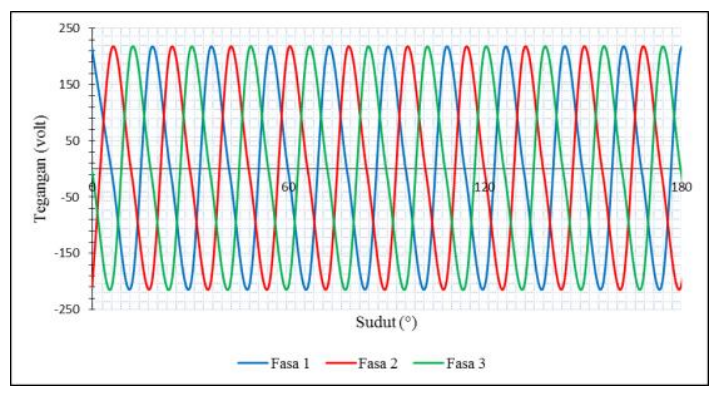

Gambar 4. Tegangan 3 fasa pada desain awal generator.

\section{B. Hasil Desain dengan Variabel A}

Tabel 3 menunjukkan hasil torsi denyut dari desain variabel A. Nilai efektif torsi denyut menurun sebesar 57\% dibandingkan desain awal. Gambar 5 menunjukkan nilai torsi denyut pada desain dengan variabel A. Distribusi frekuensi torsi denyut meningkat sebesar 66\%. Peningkatan distribusi frekuensi ini berarti nilai torsi denyut selama satu putaran penuh tidak lebih stabil dibandingkan desain awal.

Gambar 6 menunjukkan tegangan keluaran pada desain ini. Tegangan tiap fasa sebesar $170.3 \mathrm{~V}$ atau meningkat sebesar $1.41 \%$, resistansi tiap fasa pada kondisi beban penuh sebesar 113.2 $\Omega$, arus beban penuh sebesar 2.25 A, dan daya tiga fasa sebesar 763,8 W. Daya keluaran maksimal pada variable $\mathrm{C}$ adalah 1080.2 atau mengalami peningkatan sebesar $0.86 \%$.

\section{Hasil Desain dengan Variabel B}

Gambar 7 menunjukkan hasil nilai torsi denyut pada desain dengan variabel B. Distribusi frekuensi meningkat sebesar $157 \%$ dibandingkan desain awal. Nilai torsi denyut sebesar $0.459 \mathrm{Nm}$ atau turun sebesar $62 \%$ dibandingkan desain awal.

Gambar 8 menunjukkan grafik hasil tegangan keluaran desain pada variabel B. Tegangan keluaran tiap fasa pada desain ini sebesar $171.8 \mathrm{~V}$ atau meningkat sebesar $2.31 \%$, resistansi tiap fasa pada kondisi beban penuh sebesar 114.1 $\Omega$, arus beban penuh tiap fasa sebesar $2.25 \mathrm{~A}$, dan daya keluaran maksimal sebesar 1089.6 W atau meningkat sebesar $1.74 \%$ dibandingkan desain awal.

Tabel 3. Hasil perbandingan nilai torsi denyut pada semua desain generator.

\begin{tabular}{|c|c|c|}
\hline Konfigurasi desain & Nilai efektif $(\mathrm{Nm})$ & Distribusi frekuensi \\
\hline Desain awal & 1.214 & 0.080 \\
\hline Desain variabel A & 0.521 & 0.132 \\
\hline Desain variabel B & 0.459 & 0.205 \\
\hline Desain Variabel C & 0.513 & 0.208 \\
\hline
\end{tabular}

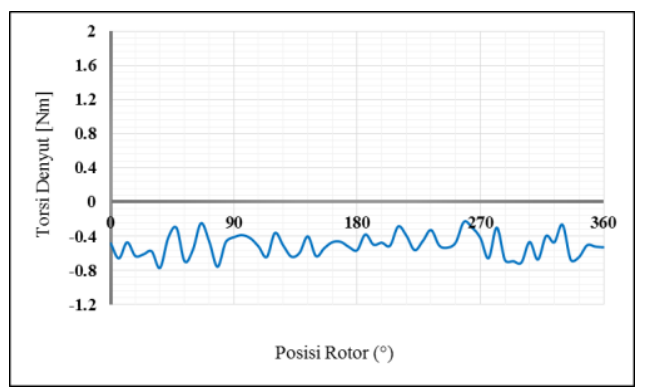

Gambar 5. Grafik nilai torsi denyut pada desain dengan variabel A. 


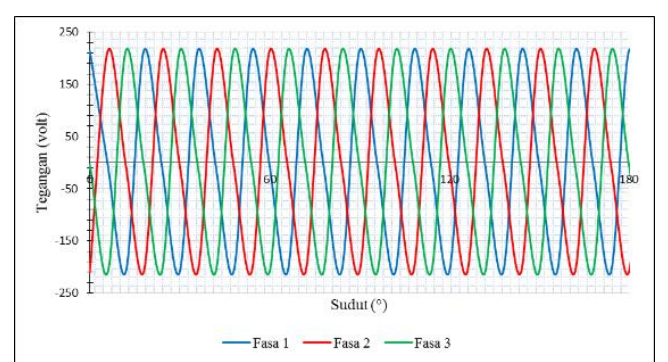

Gambar 6. Tegangan 3 fasa pada desain dengan variabel A.

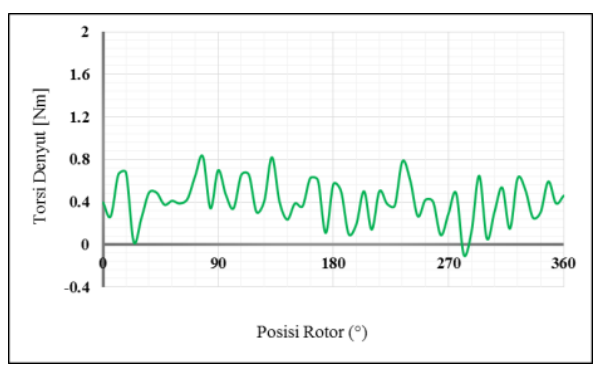

Gambar 7. Grafik nilai torsi denyut pada desain dengan variabel B.

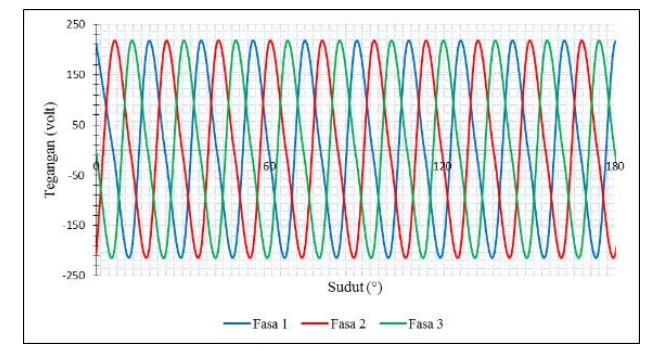

Gambar 8 Tegangan 3 fasa pada desain dengan variabel B.

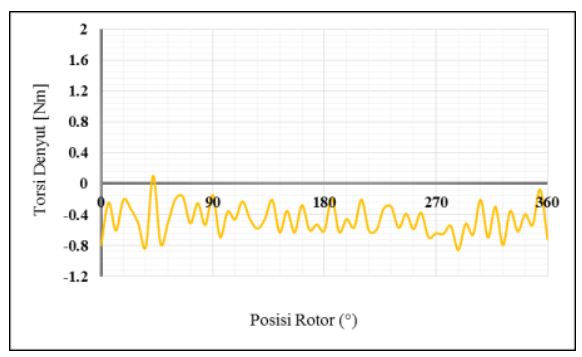

Gambar 9. Grafik nilai torsi denyut pada desain dengan variabel C.

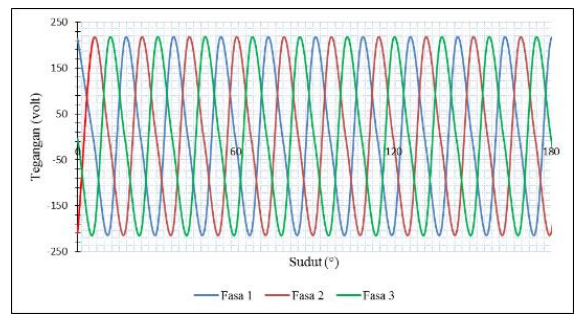

Gambar 10. Tegangan 3 fasa pada desain dengan variabel C.

\section{Hasil Desain dengan Variabel C}

Desain dengan variabel $\mathrm{C}$ menunjukkan kenaikan distribusi frekuensi yang paling signifikan, yaitu sebesar $162 \%$. Hal ini berarti desain ini adalah desain dengan resiko getaran mesin paling tinggi yang menyebabkan besarnya arus eddy dan menurunkan performa daya keluaran mesin. Nilai torsi denyut menurun sebesar 58\%. Hasil torsi denyut pada desain ini ditunjukkan pad Gambar 9.

Daya keluaran maksimal pada desain ini adalah 1106.4 $\mathrm{W}$ atau meningkat secara signifikan, yaitu sebesar $3.3 \%$. Hal ini dipengaruhi oleh tegangan keluaran sebesar $174.6 \mathrm{~V}$ atau meningkat sebesar $3.94 \%$, resistansi beban penuh sebesar $116 \Omega$, dan arus beban penuh sebesar $2.25 \mathrm{~A}$. Grafik tegangan keluaran ditunjukkan pada Gambar 10.

\section{KESIMPULAN}

Berdasarkan hasil penelitian, dapat disimpulkan bahwa tegangan keluaran generator dan daya keluaran generator masing-masing berhasil ditingkatkan mencapai $3.94 \%$ dan $3.3 \%$ dibandingkan desain awal. Hal ini dikarenakan oleh menurunnya nilai efektif torsi denyut. Namun, distribusi frekuensi tidak dapat distabilkan. Hal ini menyebabkan adanya getaran pada mesin yang dapat menimbulkan arus eddy, kemudian daya keluaran generator tidak dapat meningkat secara signifikan.

\section{REFERENSI}

[1] S. Pakpahan, Pemetaan Energi Angin untuk Pemanfaatan dan Melengkapi Peta Potensi SDA Indonesia. Teks Orasi Pengukuhan Ahli Peneliti Utama Lembaga Penerbangan dan Antariksa Nasional.

[2] A. B. Letelier, D. A. Gonzalez, J. A. Tapia, R. Wallace, and M. A. Valenzuela, "Cogging Torque Reduction in an Axial Flux PM Machine via Stator Slot Displacement and Skewing," IEEE Trans. Ind. Appl., vol. 43, no. 3, pp. 685-693, May 2007, doi: 10.1109/TIA.2007.895738.

[3] X. Wei and K. Yang, "Research of stator displacement technique in multistage axial-flux permanent magnet machines," in 2015 IEEE Magnetics Conference (INTERMAG), 2015, pp. 1-1, doi: 10.1109/INTMAG.2015.7157600.

[4] P. Sivachandran, P. Venkatesh, and N. Kamaraj, "Cogging torque reduction in Dual-Rotor Permanent Magnet Generator for Direct Coupled Stand-Alone Wind Energy Systems," in 2008 IEEE International Conference on Sustainable Energy Technologies, 2008, pp. 24-28, doi: 10.1109/ICSET.2008.4746966.

[5] D. C. Hanselman, Brushless permanent magnet motor design. Lebanon, Ohio: Magna Physics Publishing, 2006.

[6] A. R. Pramurti and O. Y. Hutajulu, "The Design of Radial Flux Permanent Magnet Generator on Low Speed Wind Turbine to Reduce Cogging Torque," in 2018 Electrical Power, Electronics, Communications, Controls and Informatics Seminar (EECCIS), 2018, pp. 68-72, doi: 10.1109/EECCIS.2018.8692988.

[7] C. Liu, J. Zhu, Y. Wang, G. Lei, and Y. Guo, "Cogging Torque Minimization of SMC PM Transverse Flux Machines Using Shifted and Unequal-Width Stator Teeth," IEEE Trans. Appl. Supercond. 
vol. 26, no. 4, pp. 1-4, Jun. 2016, doi: 10.1109/TASC.2016.2543959.

[8] G.-C. Lee and T.-U. Jung, "Cogging torque reduction design of dual stator radial flux permanent magnet generator for small wind turbine," 2013, pp. $25-89, \quad$ doi: 10.1109/TENCONSpring.2013.6584422.

[9] G.-C. Lee and T.-U. Jung, "Design study of dual stator Radial Field Permanent Magnet generator for small wind turbine," 2012, pp. 1349-1351, doi: 10.1109/VPPC.2012.6422685.

[10] P. A. Breeze, Power generation technologies. Oxford: Newnes, 2005.

[11] N. Idayanti and Dedi, "Karakterisasi Komposisi Kimia Magnet NdFeB dengan Disfersive Spectroscopy (EDS)," J. Elektron., vol. Vol. 6, No 2, Desember 2006.

[12] H. A. Gabbar, R. Islam, M. U. Isham, and V. Trivedi, "Risk-based performance analysis of microgrid topology with distributed energy generation," Int. J. Electr. Power Energy Syst, vol. 43, no. 1, pp. 1363-1375, Dec. 2012, doi: 10.1016/j.ijepes.2012.05.061.

[13] Zaheeruddin, R. Kumar, A. Kumar, and V. K. Jain, "Mitigation of $\mathrm{CO} 2$ emission in conventional power generation with renewable energy," in 2015 International Conference on Futuristic Trends on Computational Analysis and Knowledge Management (ABLAZE), 2015, pp. 734-738, doi: 10.1109/ABLAZE.2015.7154955.

[14] G.-C. Lee and T.-U. Jung, "Optimal cogging torque reduction design of dual stator radial flux permanent magnet generator," 2013, pp. 1-9, doi: 10.1109/EPE.2013.6634427. 